\title{
Adenylate Cyclase Activity During Phenotypic Variation of Bordetella pertussis
}

\author{
By R. M. BROWNLIE, * J. G. COOTE AND R. PARTON \\ Depurtment of Microbiolog!: Unicersity of Glasgow, Alexander Stone Building. \\ Garscube Estate, Bearsden. Glasgow G61 1QH, UK
}

(Received 23 February 1984; revised 9 June 1984)

\begin{abstract}
During $\mathrm{MgSO}_{4}$-induced modulation of Bordetella pertussis, adenylate cyclase activity, histamine-sensitizing activity (HSA) and the major cell-envelope polypeptides with $M_{\mathrm{r}} 28000$ and 30000 (X polypeptides) were lost synchronously at a rate which could be accounted for by a simple growth-dilution effect. $\mathrm{MgSO}_{4}$ and other compounds which induced the above phenotypic change caused little inhibition of adenylate cyclase activity. Nicotinic acid was the sole exception and at 4.1 mm-caused $60 \%$ inhibition of activity. Lysates of modulated cells, mixed with lysates of unmodulated cells, had no effect on either adenylate cyclase activity or HSA. Protein synthesis was a prerequisite for $\mathrm{MgSO}_{+}$-induced modulation and also for the reversal of this process. Exogenous CAMP and dibutyryl cAMP (5 mM) had no counteracting effect on $\mathrm{MgSO}_{4}$ - or nicotinic acid-induced modulation. The concentration of $\mathrm{MgSO}_{4}$ required to induce loss of the $\mathrm{X}$ polypeptides ( 10 to $11 \mathrm{~mm}$ ) was not altered by promoting adenylate cyclase activity by including an activator in the growth medium. In one culture containing $10 \mathrm{~mm}$ $\mathrm{MgSO}_{4}$ and activator, partial loss of the X polypeptides occurred and yet the extracellular cAMP concentration was twice that of cultures without activator and where full expression of the $\mathrm{X}$ polypeptides occurred. $\left[{ }^{3} \mathrm{H}\right] \mathrm{cAMP}$-binding activity was detected in cell extracts of several strains of $B$. pertussis, but antiserum against purified Escherichia coli catabolite repressor protein gave no reaction with $B$. pertussis cell extracts. Respiration rates with amino acids were similar for modulated and unmodulated variants and an avirulent strain of $B$. pertussis. These results are discussed in relation to a possible causal role for adenylate cyclase in modulation of $B$. pertussis.
\end{abstract}

\section{INTRODUCTION}

Several properties associated with the virulence of Bordetella pertussis are lost during the reversible phenotypic change, known as modulation, which occurs when the organism is grown in medium containing one of several salts or nicotinic acid (Lacey, 1960; Pusztai \& Joó, 1967; Holt \& Spasojevic, 1968; Livey et al., 1978; Dobrogosz et al., 1979; Wardlaw \& Parton, 1979; Brownlie et al., 1984). These properties include pertussigen-related activities such as histamine sensitization (see Brownlie et al., 1984), heat-labile toxin, the major cell-envelope polypeptides with $M_{\ulcorner} 28000$ and 30000 (X polypeptides), filamentous haemagglutinin, agglutinogen 1, cytochrome $d_{62}$, and adenylate cyclase activity. These properties are also lost during a similar change termed phase degradation, which occurs when $B$. pertussis is repeatedly subcultured in vitro (Leslie \& Gardner, 1931; Roberts \& Ospeck, 1942; Keogh \& North, 1948; Eldering et al., 1962; Aprile, 1972; Parton \& Wardlaw, 1975; Parton \& Durham, 1978; Dobrogosz et al., 1979). Until recently this change was thought to be irreversible (Weiss \& Falkow, 1984). The virulent and avirulent phenotypes which the modulation process generates are referred to as X-and C-mode, respectively, whereas the counterpart phenotypes of phase degradation are often referred to as phase I and phase IV, respectively.

Abbretiations: CRP, catabolite repressor protein: HSA. histamine-sensitizing activity.

(0)101-1810 C 1985 SGM 
Adenylate cyclase plays a key regulatory role in the expression of several proteins with diverse functions in the enterobacteria (Pastan \& Adhya, 1976; Botsford, 1981), including some associated with virulence (Eisenstein et al., 1981; Martinez-Cadena et al., 1981). Hewlett et al. (1979a) and Wardlaw \& Parton (1979) suggested that the adenylate cyclase in B. pertussis may play a similar regulatory role in the expression of virulence factors. In our accompanying paper (Brownlie et al., 1984), it was shown that loss of adenylate cyclase activity was always accompanied by loss of histamine-sensitizing activity (HSA) and the $\mathrm{X}$ polypeptides during modulation that was induced in a variety of ways. The adenylate cyclase of B. pertussis is unusual in two respects; it is activated by calmodulin (Goldhammer et al., 1981) and is largely extracytoplasmic in location (Hewlett et al., 1976). The purpose of this investigation was to assess whether or not the loss of adenylate cyclase activity during modulation had a causal or coincidental relationship with the loss of the other properties.

\section{METHODS}

Bacterial strains. Bordetella pertussis TAB I was isolated pernasally, before the death of an infant and was obtained from Professor G. T. Stewart, Ruchill Hospital, Glasgow, UK. Strain 18334 was a vaccine strain obtained from Connaught Laboratories, Toronto, Canada, and B. pertussis D30042 Phase I and D30042 Phase IV were obtained from Dr J. Dolby, Clinical Research Centre, Harrow, London, UK. Strain 18323 was virulent for mice challenged by the intracerebral route and was obtained from Dr F. Sheffield, National Institute of Biological Standards and Control, Holly Hill, Hampstead, London NW3 6RB. UK. Escherichia coli $1100 \mathrm{HfrH}$, thiA, which expresses wild-type $c \mathrm{ca} a^{+}$and $c r p^{+}$characterisitics, and its derivative strain $5333 \mathrm{crp}$ were obtained from $\operatorname{Dr} \mathrm{C}$. R. Harwood, The Medical School, The University, Newcastle upon Tyne, UK. Strains of B. pertussis were stored at $-70^{\circ} \mathrm{C}$ as cell suspensions in a medium consisting of Casamino acids (Difco) $\left(10 \mathrm{~g} \mathrm{l}^{-1}\right), \mathrm{MgCl}_{2} \cdot 6 \mathrm{H}_{2} \mathrm{O}\left(0 \cdot 1 \mathrm{~g} \mathrm{l}^{-1}\right)$, $\mathrm{NaCl}\left(5 \mathrm{~g} \mathrm{l}^{-1}\right), \mathrm{CaCl}_{2}\left(16 \mathrm{mg} \mathrm{l}^{-1}\right)$, glycerol $(10 \%, \mathrm{v} / \mathrm{v}), \mathrm{pH} 7 \cdot 1$. Strains of $E$. coli were stored at $-70^{\circ} \mathrm{C}^{\mathrm{C}}$ as cell suspensions in physiological saline containing $10 \%(\mathrm{v} / \mathrm{v})$ glycerol.

Growth of organisms. Strains of B. pertussis were grown on Bordet-Gengou medium (Gibco-Biocult Diagnostics, Paisley, UK) containing $20 \%(\mathrm{v} / \mathrm{v})$ defibrinated horse blood (Gibco-Biocult) for $72 \mathrm{~h}$ at $35^{\circ} \mathrm{C}$ in a moist atmosphere. A loopful of such cultures was used to inoculate $100 \mathrm{ml}$ Stainer \& Scholte medium (SS-X; Stainer \& Scholte, 1971 ) contained in $250 \mathrm{ml}$ dimpled flasks. ('-mode cells were obtained by growing B. pertussis in SS-C medium (SS$\mathrm{X}$ medium with $\mathrm{NaCl}$ replaced by $\left.5 \mathrm{~g} \mathrm{MgSO}_{4} \cdot 7 \mathrm{H}_{2} \mathrm{Ol}^{-1}\right)$. When $\mathrm{X}$ - and $\mathrm{C}$-Hornibrook medium was used, this was made up as described previously (Wardlaw et al., 1976). Commercial bovine catalase is a convenient source of adenylate cyclase activator (calmodulin) and this was present in the medium for those experiments where stated. When $B$. pertussis was grown in medium containing activator, a suspension of bovine liver catalase $\left(10 \mathrm{mg} \mathrm{ml}^{-1}\right)$ was heated at $100^{\circ} \mathrm{C}$ for $5 \mathrm{~min}$ (activator is heat-stable: Hewlett et al., $1979 \mathrm{~b}$ ), and the supernate was withdrawn, filter sterilized and added to the medium $(1 \%, \mathrm{v} / \mathrm{v})$. Flasks were shaken $(80$ r.p.m. $)$ at $35^{\circ} \mathrm{C}$ for $48 \mathrm{~h}$ in an orbital incubator. Strains of $E$. coli were grown on nutrient agar (Oxoid) for $24 \mathrm{~h}$ at $37^{\circ} \mathrm{C}$. These cultures were used to inoculate 1 litre amounts of yeast/glucose medium (Pastan et al., 1974) contained in dimpled 2 litre flasks. These were shaken $\left(80\right.$ r.p.m.) at $37^{\circ} \mathrm{C}$ for $12 \mathrm{~h}$ in an orbital incubator.

Cell disruption. When cell lysates were assayed for adenylate cyclase activity, harvested cells were resuspended in saline $\left(2.5 \mathrm{mg}\right.$ protein $\left.\mathrm{ml}^{-1}\right)$ before disruption. When cell lysates together with their culture supernate were assayed for histamine-sensitizing activity (HSA), harvested cells were resuspended to 100 opacity units in their original culture supernate before disruption. Cell lysates were prepared by passing frozen cell suspensions three times through a LK B X-press (Biotech. Stockholm. Sweden).

Adenylate cyclase and cAMP assays. These were assayed as described previously (Brownlie et al., 1984).

cAMP hinding acticity. Strains of B. pertussis were grown in SS-X or SS-C medium for $48 \mathrm{~h}$ and $E$. coli strains were grown for $12 \mathrm{~h}$ in yeast/glucose medium. Harvested cells were resuspended in $10 \mathrm{~mm}$-Tris/acetate, $1.2 \mathrm{~mm}$ potassium acetate, $0.1 \mathrm{~mm}$-dithiothreitol, $25 \mu \mathrm{M}$-EDTA, $\mathrm{pH} 8.2$, passed through an X-press three times and centrifuged at $100000 \mathrm{~g}$ for $\mathrm{I}$. Supernates were removed and incubated at 4 ' $\mathrm{C}$ overnight with pancreatic deoxyribonuclease $\left(5 \mu \mathrm{g} \mathrm{ml}^{-1}\right)$ and pancreatic ribonuclease $\left(5 \mu \mathrm{g} \mathrm{ml}^{-1}\right)$. Samples were assayed for $\left[{ }^{3} \mathrm{H}\right] \mathrm{cAMP}$ binding activity using the method of Pastan et al. (1974).

Aerobic catabolism of amino acids. B. pertussis was subcultured twice in either SS-X or SS-C medium. Cultures were harvested after growth for $24 \mathrm{~h}$ and cells were washed twice in SS buffer $(50 \mathrm{~mm}-\mathrm{Tris} / \mathrm{HCl}, 43 \mathrm{~mm}-\mathrm{NaCl}$, $3.7 \mathrm{mM}-\mathrm{KH}_{2} \mathrm{PO}_{4}, 2.7 \mathrm{~mm}-\mathrm{KCl}, 0.5 \mathrm{~mm}-\mathrm{MgCl}_{2}, 0.2 \mathrm{~mm}-\mathrm{CaCl}_{2}, \mathrm{pH} 7.3$ ). Washed cells were resuspended in $\mathrm{SS}$ buffer to $15 \mathrm{mg}$ dry wt ml-1 and incubated at $35^{\circ} \mathrm{C}$ for $15 \mathrm{~min}$, to use up endogenous substrates and thereafter at $4{ }^{\circ} \mathrm{C}$. Respiration rates were measured using a Clark oxygen electrode (Yellow Springs Instrument Co., Yellow Springs. Oh., USA). After determining the endogenous respiration rate, substrate was added to the chamber to give a final concentration of $18 \mathrm{~mm}$. 
Histamine-sensitizing actitity ( $H S A)$. Harvested cells were resuspended in saline to 100 opacity units, heat-killed ( $56^{\circ} \mathrm{C}$ for $30 \mathrm{~min}$ ) and assayed and evaluated for HSA by the probit method as described by Wardlaw et al. (1976). Cell lysates were heat-treated $\left(56^{\circ} \mathrm{C}\right.$ for $30 \mathrm{~min}$ ) and assayed for HSA in only those experiments where stated.

Haemagglutinating actirity. Assays were done using microtitre trays. Wells contained $50 \mu \mathrm{l}$ of bacterial cell suspension (in physiological saline) in a series of doubling dilutions and $50 \mu \mathrm{l}$ of $2 \%(\mathrm{v} / \mathrm{v})$ horse red-blood cell suspension. After incubating the trays for several hours at $4 \% \mathrm{C}$, the haemagglutinin titre was recorded as the reciprocal of the highest dilution giving complete haemagglutination.

Slab-gel electrophoresis. Harvested cells were washed once in physiological saline, resuspended to $2 \mathrm{mg}$ protein $\mathrm{ml}^{-1}$ and whole cell proteins were analysed by SDS-PAGE using the methods described previously (Wardlaw et al. 1976; see Brownlie et al., 1984).

Ouchterlony double-diffusion precipitin test. Samples ( $100 \mu \mathrm{l})$ were added to wells $(5 \mathrm{~mm}$ diameter, $5 \mathrm{~mm}$ apart) in

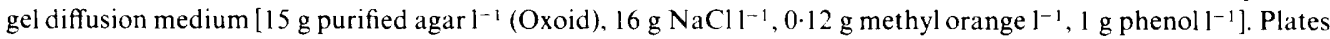
were examined after storage in sealed containers at room temperature for several days.

'Crossed-oter' immunoelectrophoresis. This was done using the method described by Culliford (1964).

Standardization of cell suspensions. Protein was estimated by the method of Herbert et al. (1969) with bovine serum albumin as a standard. For convenience, a standard curve relating dry weight and protein concentration to optical density was used. For HSA determinations, cell suspensions were standardized (before being heat-killed) by comparison with the Fifth International Reference of Opacity (World Health Organization International Laboratory for Biological Standards. National Institute for Biological Standards and Control, Holly Hill, London NW3 6RB, UK).

Chemicals and reagents. Nucleotides and commercial enzymes were from Sigma and tritiated compounds were from Amersham. Goat anti-E. coli catabolite repressor protein was obtained from Dr I. Pastan, Laboratory of Molecular Biology, National Cancer Institute, NIH, Bethesda, Md, USA.

\section{RESULTS}

\section{Rate of $\mathrm{MgSO}_{4}$-induced modulation}

Adenylate cyclase activity, HSA and the $\mathrm{X}$ polypeptides declined rapidly during $\mathrm{MgSO}_{4}$ induced modulation (Fig. 1). These properties did not change greatly in control experiments where similar inocula were introduced in SS-X medium. It was difficult to assess the rate of loss of HSA accurately due to the large $95 \%$ confidence limits obtained (e.g. the confidence limits for HSA potency relative to the inoculum for one experiment were $28-110 \%$ at $4 \mathrm{~h}, 8-30 \%$ at $8 \mathrm{~h}$ and $4-19 \%$ at $20 \mathrm{~h}$ ). Densitometer traces of SDS-PAGE profiles of whole cells at various stages of modulation revealed not only loss of the X polypeptides $\left(M_{\mathrm{r}} 28000\right.$ and 30000$)$ but also loss of at least two other gel bands each with $M_{\mathrm{r}}$ of approximately 100000 . These may correspond to the bands with $M_{\mathrm{r}} 98000$ and 88000 which were reported by Dobrogosz et al. (1979) to be lost during modulation. Another minor polypeptide with $M_{\mathrm{r}}$ of approximately 20000 appeared to decrease in intensity during modulation. Loss of adenylate cyclase activity, HSA and the X polypeptides occurred in a synchronous manner and correlated closely with the theoretical loss assuming no synthesis de novo and no inactivation or destruction (Fig. 1). This suggests that the loss of these properties could be accounted for by complete repression of the synthesis of adenylate cyclase, pertussigen and the $\mathrm{X}$ polypeptides upon transfer of cells to SS-C medium. The extracellular cAMP concentration increased gradually during growth in SS-X medium but remained constant, or declined slightly during growth in SS-C medium (Fig. 2).

\section{Possible involvement of inhibitors in modulation}

The low concentration of extracellular cAMP in C-mode cultures (Brownlie et al., 1984) which did not change greatly during growth in SS-C medium (Fig. 2) may have resulted from inhibition of adenylate cyclase activity by pro-C-mode substances. These substances were therefore tested for their effect on adenylate cyclase activity when present in the assay mixture (Table 1). Both nicotinic acid and nicotinamide caused substantial inhibition of enzyme activity (about $60 \%$ ). Sodium salts, including the pro-X-mode salt $\mathrm{NaCl}$, caused mild inhibition of activity whereas $\mathrm{MgSO}_{4}$ increased activity slightly.

To test whether SS-C medium inhibited the production of extracellular cAMP, washed Xmode cells were resuspended in SS-X or SS-C medium supplemented with chloramphenicol to 


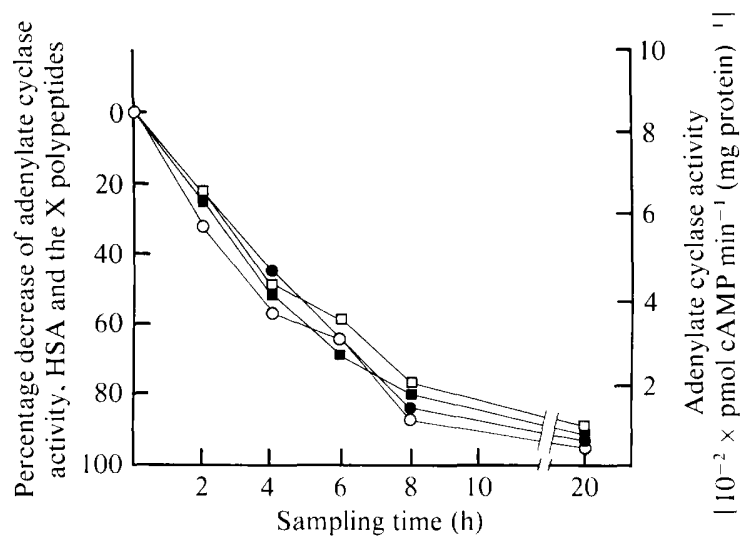

Fig. 1. Loss of adenylate cyclase activity, HSA and the X polypeptides during modulation of $B$. pertussis. SS-C medium $(1.25 \times$ normal strength $)$, temperature equilibrated at $35^{\circ} \mathrm{C}$, received a $20 \%(\mathrm{v} / \mathrm{v})$ inoculum from a $48 \mathrm{~h} \mathrm{SS-X}$ culture of strain TAB I. At intervals, cells were harvested, resuspended in saline and assayed for adenylate cyclase activity $(O)$, heat-treated $\left(56^{\circ} \mathrm{C}\right.$ for $\left.30 \mathrm{~min}\right)$ and assayed for $\mathrm{HSA}$ (O), and washed once in saline and analysed by SDS-PAGE. The intensities of the $\mathrm{X}$ polypeptide gel bands $(\square)$ were determined by densitometer traces and were standardized against the major gel band, $M_{\mathrm{r}} 37000$, which remained relatively constant during growth. The theoretical loss of any property assuming complete repression of synthesis $(\boldsymbol{D})$ was calculated using a growth curve based on optical density determinations. Similar data were obtained in a second determination.

Table 1. Effect of salts and organic acids on adenylate cyclase activity of $B$. pertussis

Strain TAB I was grown for $48 \mathrm{~h}$ in SS-X medium. Harvested intact cells and cell lysates were assayed for adenylate cyclase activity with various additives present in the assay mixture.

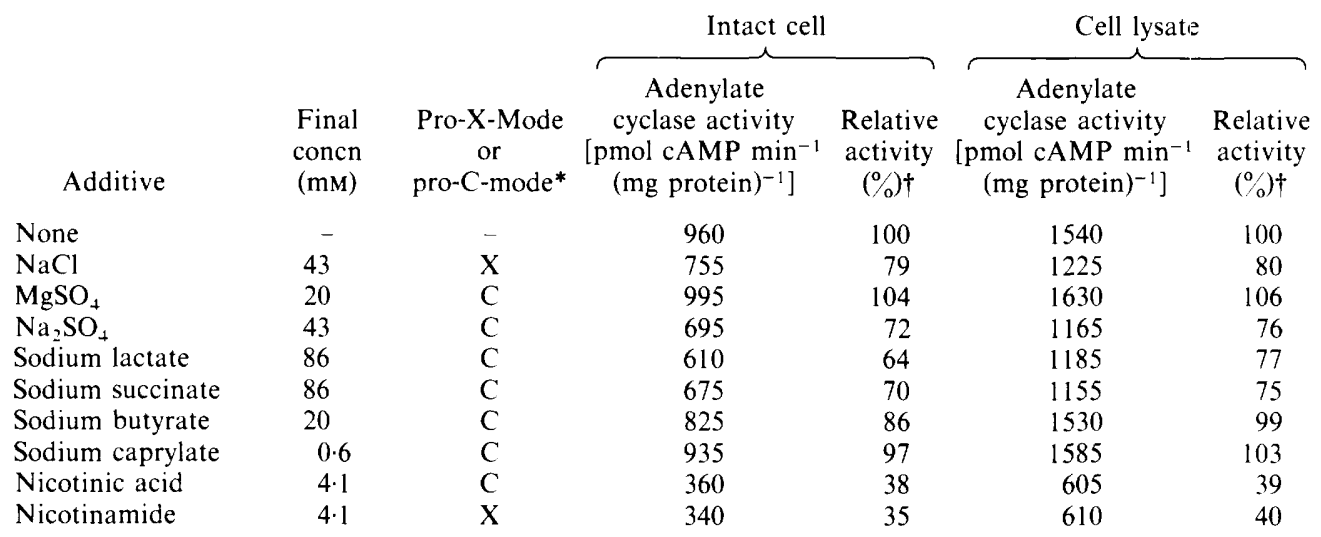

* See Wardlaw et al. (1976) and Brownlie et al. (1984).

+ Activity in Tricine buffer alone equivalent to $100 \%$.

prevent differential growth, and the supernate was removed at intervals and assayed for cAMP. One set of cell suspensions contained adenylate cyclase activator. The rate of production of extracellular cAMP was the same in both SS-X and SS-C medium, indicating that SS-C did not directly inhibit excretion of cAMP from X-mode cells (Fig. 3). This study also demonstrated that SS-C medium did not interfere with the effect of activator in increasing the production of extracellular cAMP (Fig. 3).

The possibility that a factor was produced during modulation which specifically inactivated $\mathrm{X}$-mode-specific activities was tested by mixing $\mathrm{X}$ - and $\mathrm{C}$-mode cell lysates and assaying for adenylate cyclase activity and HSA. For HSA experiments, harvested cells were resuspended to 100 opacity units in culture supernate before cell disruption in case destructive factors were 


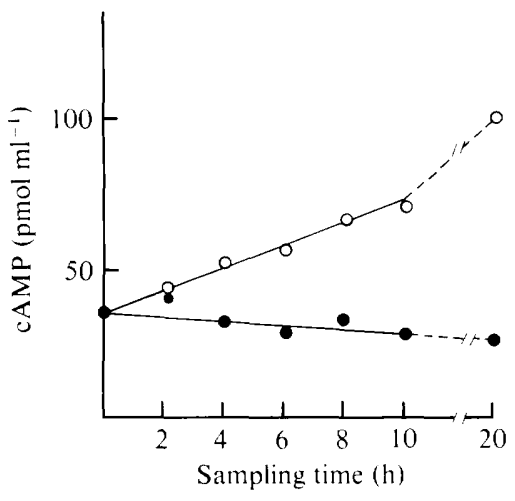

Fig. 2

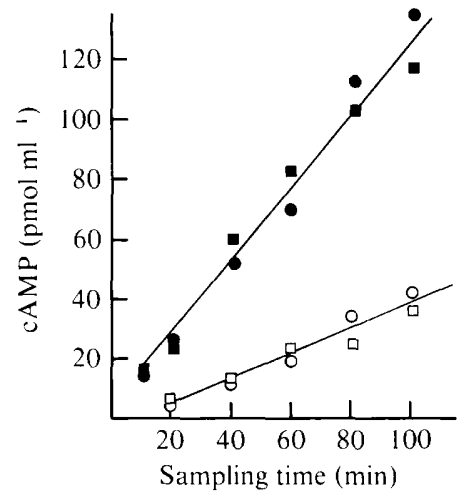

Fig. 3

Fig. 2. Concentration of extracellular cAMP during growth of $B$. pertussis in X and $\mathrm{C}$ medium. SS-X and SS-C medium $\left(1.25 \times\right.$ normal strength), temperature equilibrated at $35^{\circ} \mathrm{C}$, received a $20 \%(\mathrm{v} / \mathrm{v})$ inoculum of a $48 \mathrm{~h} \mathrm{SS-X}$ culture of strain TAB I. Supernate was assayed for cAMP after samples were removed at intervals during growth in SS-X $(O)$ and SS-C $(O)$ medium. Similar data were obtained in a second determination.

Fig. 3. Effect of $\mathrm{MgSO}_{4}$ and adenylate cyclase activator on the production of extracellular cAMP by resuspended X-mode $B$. pertussis. Harvested cells of strain TAB I from a $48 \mathrm{~h} \mathrm{SS-X}$ culture were washed once and resuspended in medium supplemented with chloramphenicol $\left(100 \mu \mathrm{g} \mathrm{ml}^{-1}\right)$ to give $15 \mathrm{mg} \mathrm{dry}$ wt $\mathrm{ml}^{-1}$. Suspensions $(10 \mathrm{ml})$ were incubated in $150 \mathrm{ml}$ flasks in an orbital shaker at $35^{\circ} \mathrm{C}$. At intervals, samples were removed and assayed for cAMP. Media were SS-X $(O)$, SS-X with adenylate cyclase activator $\left(100 \mu \mathrm{g}\right.$ bovine catalase $\left.\mathrm{ml}^{-1}\right)(\mathbf{O})$, SS-C $(\square)$, and SS-C with adenylate cyclase activator $(\boldsymbol{\square})$. Results were similar in a second determination.

\section{Table 2. Adenylate cyclase and HSAs of cell lysates and lysate mixtures of B. pertussis}

For the adenylate cyclase activity experiments, strains were grown in SS-X or SS-C medium for $48 \mathrm{~h}$. For the HSA experiments, strain TAB I was grown in SS-X or SS-C medium for $48 \mathrm{~h}$ and strain 18334 was grown in $\mathrm{X}$ - and $\mathrm{C}$-mode Hornibrook medium for $48 \mathrm{~h}$. Lysates were prepared as described in Methods, supplemented with chloramphenicol $\left(100 \mu \mathrm{g} \mathrm{ml}^{-1}\right)$, to prevent contamination, and incubated statically at $35^{\circ} \mathrm{C}$ for $24 \mathrm{~h}$ ( $24 \mathrm{~h}$ growth is normally required for modulation). $\mathrm{X}$ - and $\mathrm{C}$-mode cell lysates were mixed in equal volumes; NT, not tested.

$$
\begin{aligned}
& \text { Adenylate } \\
& \text { cyclase activity } \\
& \text { MP } \min ^{-1}(\text { mg protein })^{-1} \text { ] }
\end{aligned}
$$

Sample

$$
\text { Strain ... TAB I } 18334
$$

1390

55

630

$$
\begin{array}{r}
950 \\
45 \\
225
\end{array}
$$

$\begin{array}{cc}\overbrace{\text { TAB I }}^{\text {HSA potency }}\left(\%_{0}^{*}\right)^{*} & 18334 \\ \text { NT } & 100 \\ 100 & 74(40,136) \\ <7 \cdot 5_{+}^{+} & 6 \cdot 2(3 \cdot 1,12) \\ 37(18,75) & 68(37,125) \\ 50 & 54\end{array}$

Expected activity of mixture

* HSA of X-mode cell lysate before incubation in strain 18334, and after incubation in strain TAB I, were taken as $100 \%$. The numbers in parentheses refer to $95 \%$ confidence limits.

† The expected activity was calculated assuming no inactivation from $\mathrm{C}$-mode cell lysate (i.e. the means of the individual $\mathrm{X}$ - and $\mathrm{C}$-mode cell lysate activities after incubation).

$\ddagger$ No animals died using 20 opacity units $\mathrm{ml}^{-1}$ as highest dose.

released into the medium. Adenylate cyclase activities and HSAs of $\mathrm{X}$ - plus $\mathrm{C}$-mode cell lysate mixtures were similar to those expected assuming that no destructive factors were present (Table 2). This was also the case for the HSA of an X-plus C-mode cell lysate mixture of strain 18334 


\section{Table 3. Effect of chloramphenicol on $C$ - and $X$-modulation of $B$. pertussis}

Media received a $10 \%(\mathrm{v} / \mathrm{v})$ inoculum from either a $48 \mathrm{~h} \mathrm{SS-X}$ or SS-C culture. After $48 \mathrm{~h}$ incubation at $35^{\circ} \mathrm{C}$ harvested cells were assayed for intact-cell adenylate cyclase activity, HSA and the $\mathrm{X}$ polypeptides. Chloramphenicol was present at $100 \mu \mathrm{g} \mathrm{ml}^{-1}$. The adenylate cyclase activities shown are the means of two determinations; + , present; - , absent.

\begin{tabular}{|c|c|c|c|c|c|}
\hline Inoculum & Medium & Chloramphenicol & $\begin{array}{l}\text { HSA potency } \\
(\% /)^{*}\end{array}$ & $\begin{array}{c}\text { Adenylate } \\
\text { cyclase activity } \\
{\left[\text { pmol cAMP min } \text { min }^{-1}\right.} \\
\left.(\mathrm{mg} \text { protein })^{-1}\right]\end{array}$ & $\frac{\mathrm{X}}{\text { polypeptides }}$ \\
\hline \multirow{2}{*}{ SS-X-grown cells } & SS-X & $\overline{-}$ & $\begin{array}{l}100 \\
93(50,176)\end{array}$ & $\begin{array}{l}990 \\
660\end{array}$ & $\begin{array}{l}+ \\
+\end{array}$ \\
\hline & SS-C & $\begin{array}{l}- \\
+\end{array}$ & $\begin{array}{c}6(2,13) \\
100(53,189)\end{array}$ & $\begin{array}{r}15 \\
625\end{array}$ & - \\
\hline \multirow{2}{*}{ SS-C-grown cells } & SS-X & + & $\begin{array}{l}100 \\
1 \cdot 9(0 \cdot 0,6 \cdot 9)\end{array}$ & $\begin{array}{r}915 \\
10\end{array}$ & + \\
\hline & SS-C & $\bar{t}$ & $\begin{array}{l}<4 \cdot 2 \dagger \\
1 \cdot 3(0 \cdot 0,5 \cdot 5)\end{array}$ & $\begin{array}{c}<5_{t}^{+} \\
15\end{array}$ & $\begin{array}{l}- \\
-\end{array}$ \\
\hline
\end{tabular}

* HSA potency of SS-X-(without chloramphenicol) grown cells was taken as $100 \%$. The numbers in parentheses refer to $95 \%$ confidence limits.

$\dagger$ No animals died using 20 opacity units $\mathrm{ml}^{-1}$ per mouse as highest dose.

$\ddagger$ Limit of detection.

\section{Table 4. Critical concentration of $\mathrm{MgSO}_{4}$ required to induce loss of the X polypeptides}

Strain TAB I was grown for $48 \mathrm{~h}$ in SS-X medium where the $\mathrm{NaCl}$ was proportionately replaced by $\mathrm{MgSO}_{4}$. Supernate of a heat-treated $\left(100^{\circ} \mathrm{C}\right.$ for $\left.5 \mathrm{~min}\right)$ bovine catalase solution $\left(10 \mathrm{mg} \mathrm{ml}^{-1} ; 1 \% \mathrm{v} / \mathrm{v}\right)$ was added as a source of adenylate cyclase activator. Harvested cells were analysed by SDS-PAGE to determine whether the $\mathrm{X}$ polypeptides were present $(\mathrm{X})$ or absent $(\mathrm{C})$. 'I' refers to an intermediate variant where the $X$ polypeptides were partially reduced. Culture supernate was assayed for cAMP (numbers in parentheses are pmol cAMP $\mathrm{ml}^{-1}$ ); NT, not tested.

$\begin{array}{rrrrrrrrr}\mathrm{MgSO}_{4}(\mathrm{mM}) \text { in medium } & \ldots & 0 & 8 & 9 & 10 & 11 & 12 & 20 \\ \mathrm{NaCl}(\mathrm{mM}) \text { in medium } & \ldots & 43 & 26 & 24 & 22 & 19 & 17 & 0\end{array}$

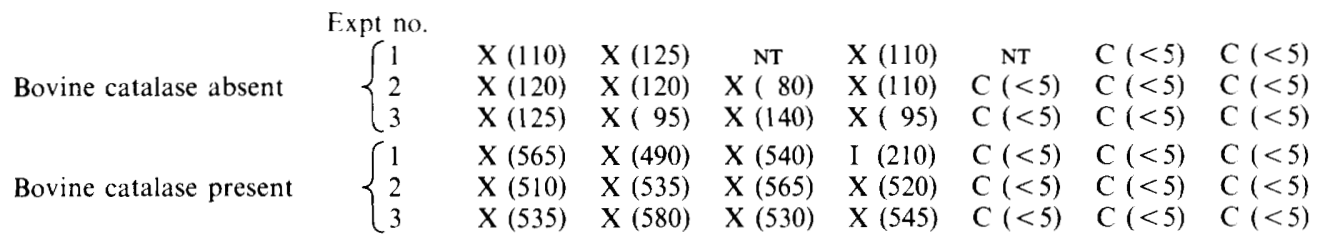

after growth in X-or C-mode Hornibrook medium. This strain and medium were used by Idigbe et al. (1981) who found HSA to be lost much more rapidly during modulation than could be accounted for by a simple dilution effect, suggesting selective destruction.

\section{Requirement for protein synthesis during modulation}

The effect of chloramphenicol on $\mathrm{MgSO}_{4}$-induced loss of adenylate cyclase activity, HSA and the X polypeptides was investigated. Strain TAB I was incubated in SS-X or SS-C meclium with and without chloramphenicol $\left(100 \mu \mathrm{g} \mathrm{ml}^{-1}\right)$. This concentration of antibiotic completely inhibited growth and incorporation of $\mathrm{L}-\left[{ }^{3} \mathrm{H}\right]$ methionine into acid-insoluble material (data not shown). Inoculation of SS-X-grown cells into SS-C medium containing chloramphenicol resulted in a drop of only $30 \%$ in adenylate cyclase activity after $48 \mathrm{~h}$, a value similar to that obtained from cells in SS-X medium with added antibiotic (Table 3). Growth in SS-C medium alone, on the other hand, promoted substantial loss of activity $(98 \%)$. cAMP in the medium did not increase substantially under conditions which did not allow bacterial growth, i.e. in medium containing chloramphenicol (data not shown). Similarly, prolonged exposure to SS-X or SS-C 
medium containing chloramphenicol caused no significant loss of HSA or the X polypeptides (Table 3). Growth in SS-C medium after inoculation with SS-X grown cells decreased HSA by $94 \%$ and caused complete loss of the X polypeptides. It can be concluded that protein synthesis is a requirement for the loss of all these properties and that incubation in SS-C medium does not bring about the destruction of these properties. The effect of chloramphenicol on $\mathrm{C}$ to $\mathrm{X}$ modulation was also investigated and, as might have been expected, the expression of adenylate cyclase activity, HSA and the $\mathrm{X}$ polypeptides also required protein synthesis (Table 3 ).

\section{Effect of added cyclic nucleotides}

Addition of either cAMP (5 mM) or $\mathrm{N}^{6}, \mathrm{O}^{2 \prime}$-dibutyryl cAMP (5 mM) to the medium had no effect in counteracting $\mathrm{MgSO}_{4}$-induced loss of adenylate cyclase activity, the $\mathrm{X}$ polypeptides and haemagglutinating activity, or nicotinic acid-induced loss of adenylate cyclase activity and the $\mathrm{X}$ polypeptides. Although it has not been shown conclusively that the nucleotides are taken up by the cells, preliminary experiments did show the incorporation of $\left[{ }^{3} \mathrm{H}\right] \mathrm{cAMP}$ and $\left[{ }^{3} \mathrm{H}\right.$ ]dibutyryl cAMP into filtered X-mode cells after incubation of the cells in SS-X or SS-C medium at rates between $0 \cdot 4-0 \cdot 6 \mathrm{nmol} \mathrm{min}^{-1}(\mathrm{mg} \text { dry } \mathrm{wt})^{-1}$.

\section{Attempts to manipulate adenylate cyclase activity}

Hewlett \& Wolff (1976) reported that NaF strongly inhibited activity of purified B. pertussis adenylate cyclase. This was confirmed in the present study where $40 \mathrm{~mm}-\mathrm{NaF}$ in the assay mixture inhibited adenylate cyclase activity of cell-lysate by $90 \%$. However, although the presence of $\mathrm{NaF}(40 \mathrm{mM}$ ) in SS-X medium partially inhibited growth it did not alter production of extracellular cAMP or the $\mathrm{X}$ polypeptides. This may be because $B$. pertussis cells might not be very permeable to $\mathrm{NaF}$.

Commercial bovine catalase is a convenient source of adenylate cyclase activator in $B$. pertussis (Hewlett et al., 1978). It was thought that this might be a useful tool for assessing the role that cAMP might play in modulation. Experiments showed that activator had little effect on the production of HSA, the X polypeptides or extracellular cAMP after $48 \mathrm{~h}$ growth in SS-C medium. When the activator was present in SS-X medium it raised production of extracellular cAMP approximately fivefold, but had no noticeable effect on HSA or the X polypeptides after $48 \mathrm{~h}$ growth. Thus it appeared that modulation conditions in SS-C medium were too severe to increase cAMP production to a detectable level, even with activator in the medium. Lacey (1960) reported that an intermediate (I) mode arose when B. pertussis was grown with a critical ratio of pro-X-to pro-C-mode salts. If cAMP played a role in modulation it was thought possible that the addition of activator to the medium might shift the critical concentration of $\mathrm{MgSO}_{4}$ required to induce modulation. Strain TAB I was grown for $48 \mathrm{~h}$ in a series of modified SS-X media where the $\mathrm{NaCl}$ was progressively replaced by $\mathrm{MgSO}_{4}$. A parallel series of cultures contained activator. The critical concentration of $\mathrm{MgSO}_{4}$ required to induce modulation, as judged by the loss of the $\mathrm{X}$ polypeptides, was $11 \mathrm{~mm}$ (Table 4 ) and this was not altered by the presence of the activator. Using batch cultures and increments of $1 \mathrm{~mm}-\mathrm{MgSO}_{4}$, it was difficult to obtain an I-mode variant showing partial loss of the $\mathrm{X}$ polypeptides. In six series of $\mathrm{MgSO}_{4} / \mathrm{NaCl}$ concentrations, an I-mode was obtained once only, suggesting that this variation to I-mode is critically dependent on the concentration of $\mathrm{MgSO}_{4}$. Extracellular cAMP was detectable only in those cultures where the $\mathrm{X}$ polypeptides were present. In cultures with activator, cAMP concentrations ranged from 490 to $580 \mathrm{pmol} \mathrm{ml}^{-1}$ while in cultures without activator, the range was 80 to $140 \mathrm{pmol} \mathrm{m}^{-1}$. The one case where an I-mode variant was obtained (where the $\mathrm{X}$ polypeptides were partially lost) was in a culture grown with activator. The extracellular cAMP concentration in this culture was $210 \mathrm{pmol} \mathrm{ml}^{-1}$, which was about twice that found in $\mathrm{X}$-mode cultures without activator.

\section{cAMP binding activity}

cAMP regulates gene transcription in $E$. coli by binding to a cytoplasmic protein termed the catabolite repressor protein (CRP). This complex (cAMP-CRP) selectively activates or inhibits gene expression (Botsford, 1981). If cAMP plays a regulatory role in gene expression in $B$. 
Table 5. $\left[{ }^{3} H\right] c A M P$ binding activity in extracts of $E$. coli and B. pertussis

E. coli strains were grown for $12 \mathrm{~h}$ in yeast/glucose medium and B. pertussis strains were grown for $48 \mathrm{~h}$ in SS-X medium. Supernates of cell lysates were assayed for $\left[{ }^{3} \mathrm{H}\right] \mathrm{cAMP}$ binding activity.

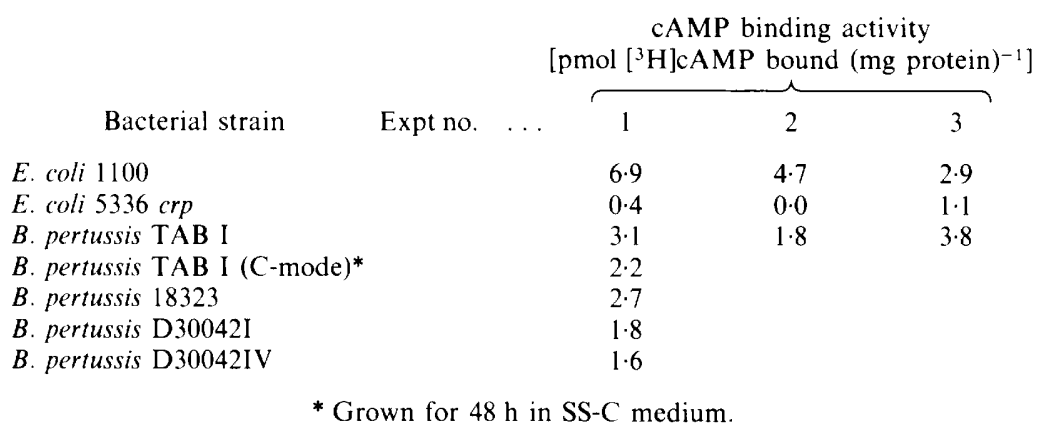

Table 6. Respiration rate of $B$. pertussis variants in the presence of different amino acids

Strain D30042I was subcultured twice for $24 \mathrm{~h}$ in either SS-X or SS-C medium and strain D30042IV was subcultured twice for $24 \mathrm{~h}$ in SS-X medium. Respiration rates were determined at $35^{\circ} \mathrm{C}$ for twice washed cells using a Clark oxygen electrode. Cells were present at $0.5 \mathrm{mg}$ dry wt $\mathrm{ml}^{-1}$ and substrate at $18 \mathrm{~mm}$. Substrate respiration rate was corrected for endogenous rate. Results are the means of three determinations $\pm \mathrm{SD}$.

\begin{tabular}{llll} 
Amino acid & \multicolumn{3}{c}{$\begin{array}{c}\text { Respiration rate } \\
{\left[\mu \mathrm{O} \mathrm{O}_{2} \min ^{-1}(\mathrm{mg} \text { dry wt })^{-1}\right]}\end{array}$} \\
\cline { 2 - 4 } L-Glutamate & $6 \cdot 3 \pm 0 \cdot 9$ & $6 \cdot 5 \pm 0 \cdot 6$ & $6 \cdot 5 \pm 0 \cdot 3$ \\
L-Aspartate & $5 \cdot 6 \pm 0 \cdot 8$ & $7 \cdot 2 \pm 1 \cdot 3$ & $6 \cdot 5 \pm 0 \cdot 2$ \\
L-Proline & $3 \cdot 5 \pm 0 \cdot 6$ & $3 \cdot 9 \pm 0 \cdot 2$ & $3 \cdot 4 \pm 0 \cdot 2$ \\
L-Serine & $2 \cdot 5 \pm 0 \cdot 3$ & $2 \cdot 9 \pm 0 \cdot 2$ & $2 \cdot 5 \pm 0 \cdot 3$ \\
L-Alanine & $2 \cdot 2 \pm 0 \cdot 3$ & $2 \cdot 4 \pm 0 \cdot 1$ & $2 \cdot 7 \pm 0 \cdot 3$ \\
Endogenous rate & $0 \cdot 2 \pm 0 \cdot 1$ & $0 \cdot 3 \pm 0 \cdot 2$ & $0 \cdot 2 \pm 0 \cdot 1$
\end{tabular}

pertussis, it is likely that the organism possesses a protein analogous to the CRP in E. coli. $\left[{ }^{3} \mathrm{H}\right] \mathrm{cAMP}$ binding activity was demonstrated in extracts of strains of $E$. coli and B. pertussis (Table 5). Low activity was detected in E. coli crp (a strain lacking a functional CRP) and binding activity in $B$. pertussis strains was midway between this strain and the wild type- $E$. coli $\mathrm{Crp}^{+}$. No significant differences were apparent between $\mathrm{X}$ - and $\mathrm{C}$-mode cells or between phase I and phase IV variants. The possible presence in B. pertussis of a protein immunologically similar to $E$. coli CRP was tested by Ouchterlony double-diffusion precipitin and 'crossed-over' immunoelectrophoresis tests using goat anti-E. coli CRP serum. In both tests, one strong and one faint precipitin line were observed against a cytoplasmic fraction of $E$. coli $\mathrm{Crp}^{+}$but none was obtained against cytoplasmic fractions of $B$. pertussis TAB I or 18334 , even at twice the protein concentration of the $E$. coli fraction.

\section{Aerobic catabolism of amino acids}

The respiration rates of $B$. pertussis variants in the presence of various amino acids were investigated to see if cAMP played a role in regulating the expression of catabolic functions in this organism as it does in the enterobacteria (Pastan \& Adhya, 1976). Washed suspensions of $B$. pertussis catabolized several amino acids at significant rates, as indicated by the utilization of $\mathrm{O}_{2}$ (Table 6). Increased respiration was not detected with D-ribose, D-glucose, D-sucrose, glycine, Lglutamine, L-arginine, L-lysine, L-threonine, L-histidine or citrate. While significant differences existed between the respiration rates in the presence of different amino acids, there were no obvious differences between the respiration rates by different variants in the presence of any particular amino acid. X-and C-mode variants of B. pertussis D30042I also utilized acetate, pyruvate, lactate, succinate and formate at rates which were similar for both variants (data not shown). 


\section{DISCUSSION}

From this study, two lines of evidence indicate that adenylate cyclase is not the target site for modulation and that low concentrations of CAMP are due to repression of adenylate cyclase synthesis, itself subject to the regulatory mechanism perturbed during modulation. Firstly, loss of intact-cell adenylate cyclase activity during $\mathrm{MgSO}_{4}$-induced modulation could be accounted for by complete repression of adenylate cyclase synthesis. Secondly, no evidence favouring direct or indirect inhibition of adenylate cyclase activity, or an inactivating mechanism, which might have occurred during modulation was obtained. Also, it is unlikely that cAMP plays a secondary role in modulation by repressing synthesis of pertussigen and the X polypeptides since : $(a)$ loss of intact-cell adenylate cyclase activity during $\mathrm{MgSO}_{4}$-induced modulation did not precede but paralleled the loss of HSA and the X polypeptides; $(b)$ after growth of $B$. pertussis in modified SS-X medium containing $10 \mathrm{~mm}-\mathrm{MgSO}_{4}$ and calmodulin, partial repression of the $\mathrm{X}$ polypeptides occurred, yet extracellular concentrations of cAMP were twice as high as those in normal SS-X cultures; $(c)$ exogenous cAMP or dibutyryl cAMP in the growth medium had no observable effect in counteracting modulation.

The time-course of $\mathrm{MgSO}_{4}$-induced modulation revealed that loss of adenylate cyclase activity, HSA and the X polypeptides occurred synchronously and could be accounted for by an immediate and complete repression of synthesis of the responsible components. This is consistent with results reported by Hall et al. (1982) who investigated the rate of loss of adenylate cyclase activity and the $\mathrm{X}$ polypeptides during $\mathrm{MgSO}_{4}$-induced modulation. However, in an analysis of six independent experiments, Idigbe et al. (1981) reported that strain 18334, grown in modified Hornibrook medium containing $\mathrm{MgSO}_{4}$, underwent a more rapid loss of pertussigenassociated activities, heat-labile toxin and the $\mathrm{X}$ polypeptides than could be accounted for by a simple growth-dilution effect. These workers suggested that selective destruction of X-mode components took place during modulation. However, they also observed a much slower growth rate (mean generation time 6 to $7 \mathrm{~h}$ ) than that observed in the present study (mean generation time $3.2 \mathrm{~h}$ ). This difference in the growth rate and the use of different strains and media may explain the difference in results from those reported here. Recently, Robinson et al. (1983) studied the rate of modulation of $B$. pertussis in continuous culture. These workers also noted that the $\mathrm{X}$ - and $\mathrm{C}$-mode transition took place faster than the theoretical washout rate, again suggesting selective destruction of $\mathrm{X}$-mode properties. Selective destruction may be noticeable only with a slow growth rate.

There was no evidence for destructive or inactivation factors for pertussigen or adenylate cyclase when X-and C-mode cell lysates were mixed together. However, moderate destruction or inactivation of pertussigen might not be noticed due to the large $95 \%$ confidence limits obtained for the HSA tests. It is also possible that destructive mechanisms require the integrity of intact cells or are extremely labile. Synthesis of selectively destructive or inactivating factors would be a rather inefficient way to control the physiology of an organism, but it is not known if modulation has a real counterpart in nature.

Previous studies have shown that extracellular concentrations of cAMP are much lower after growth in C media than after growth in X media (Parton \& Durham, 1978; Hall et al., 1982; Brownlie et al., 1984). Low concentrations of extracellular cAMP after growth in C media cannot be accounted for by direct inhibition of adenylate cyclase activity by pro-C-mode salts, as most of these caused no more inhibition than did the pro-X-mode salt $\mathrm{NaCl}$. The moderate inhibition caused by $\mathrm{NaCl}, \mathrm{Na}_{2} \mathrm{SO}_{4}$, sodium succinate and sodium butyrate was presumably due to $\mathrm{Na}^{+}$ions which Hewlett \& Wolff (1976) reported to cause mild inhibition of adenylate cyclase activity. The inhibition caused by nicotinic acid and nicotinamide was more marked (about $60 \%$ loss of activity). Growth in SS-X medium containing nicotinic acid resulted in extracellular concentrations of cAMP less than $5 \%$ of those after growth in normal SS-X medium (Brownlie $e t$ $a l ., 1984)$. It is unlikely that the observed $60 \%$ inhibition of adenylate cyclase by nicotinic acid fully accounts for this. Nicotinic acid-induced modulation is probably not due to nicotinic acid inhibition of adenylate cyclase activity since nicotinamide, which also caused $60 \%$ inhibition of adenylate cyclase activity, does not induce modulation (Wardlaw et al., 1976). Differences in the amounts of extracellular cAMP in X-and C-mode cultures cannot be attributed to differences in 
energy charge as intracellular pools of ATP are similar for X-and C-mode cells (Ezzell et al., 1981).

After incubation of X-mode B. pertussis in SS-X and SS-C medium supplemented with chloramphenicol, the specific activity of intact-cell adenylate cyclase was about 60 to $80 \%$ of that after growth in SS-X medium, whereas after growth in SS-C medium, activity was about 1.0 to $2.5 \%$ of that after growth in SS-X. This observation suggests that adenylate cyclase is a relatively stable enzyme and that the loss of activity observed during modulation is not due to direct inactivation by prolonged exposure to the medium, but requires growth or protein synthesis. Similarly, loss of HSA and the X polypeptides during modulation required growth or protein synthesis. Chloramphenicol also prevented the bacteria regaining these properties during $\mathrm{C}$ to $\mathrm{X}$ modulation, presumably because the proteins have to be synthesized de novo as opposed to being reactivated.

So far as is known, all cAMP regulatory systems in bacteria require a functional CRP although cAMP-binding proteins have been identified in only a few bacteria, e.g. E. coli, Salmonella typhimurium, Caulobacter crescentus, Myxococcus xanthus, Beneckea harveyi and Alcaligenes eutrophus (Pastan \& Adhya, 1976; Shapiro, 1976; Orlowski, 1980; Nealson \& Hastings, 1979 : Tait et al., 1981). In this study, $\left[{ }^{3} \mathrm{H}\right] \mathrm{cAMP}$ binding activity was detected in several strains of $B$. pertussis and, on average, was approximately half that obtained from the wild-type $E$. coli $\mathrm{Crp}^{+}$ and approximately four times that obtained for E. coli crp. It is not known whether this binding activity is attributable to a protein with a real physiological function. Anti-E. coli CRP gave a clear precipitin reaction with a cytoplasmic $E$. coli fraction, but gave no reaction with $B$. pertussis cytoplasmic fractions. Using this same antiserum, Ouchterlony double-diffusion studies showed cross-reactivity between purified E. coli CRP and cell extracts of E. coli, Proteus mirabilis, Photobacterium fisheri, Klebsiella aerogenes, S. typhimurium and Caulobacter crescentus (Anderson \& Pastan, 1973). The CRP of Beneckea harceyi is also immunologically homologous with that of $E$. coli (Nealson \& Hastings, 1979). To the authors' knowledge, there have been no reports of a CRP which does not react with anti-E. coli CRP.

Of 11 amino acids tested, washed suspensions of $B$. pertussis aerobically catabolized only Lglutamate, L-aspartate, L-proline, $\mathrm{L}$-serine and L-alanine at detectable rates. This is consistent with the findings of Jebb \& Tomlinson (1951). While significant differences existed between respiration rates in the presence of different amino acids, the respiration rates of the variants were similar with any particular amino acid. The fact that the C-mode and phase IV variants produced lower concentrations of cAMP during growth than did the X-mode variant suggests that cAMP was not involved in the regulation of the permeases or enzymes required for amino acid utilization. It also indicates that the mechanisms of modulation and phase degradation do not alter uptake of amino acids.

Three observations suggest that during the course of evolution adenylate cyclase may have adopted different physiological roles in E. coli and B. pertussis. (a) A large proportion of the adenylate cyclase activity in $B$. pertussis is extracytoplasmic or is secreted into the medium. (h) B. pertussis adenylate cyclase shows a marked responsiveness to calmodulin. (c) A protein immunologically similar to $E$. coli CRP could not be detected in $B$. pertussis. This may be related to the differences in physiology of the two organisms: $E$. coli is a facultative anaerobe which utilizes sugars preferentially as sources of energy whereas $B$. pertussis is a strict aerobe which utilizes only amino acids as sources of energy.

It has been suggested that adenylate cyclase in $B$. pertussis plays a role in virulence by altering cAMP-related functions in the host. Confer \& Eaton (1982) reported that after incubating neutrophils with $B$. pertussis extracts, several functions of the neutrophils were altered and the intracellular amount of cAMP in the neutrophils was higher than reported previously. In addition, the neutrophils had a high adenylate cyclase activity, which because of its heat stability $\left(100^{\circ} \mathrm{C}\right.$ for $\left.5 \mathrm{~min}\right)$, was attributed to the presence of the $B$. pertussis enzyme. In the present study, however, $100^{\circ} \mathrm{C}$ for $10 \mathrm{~min}$ destroyed all detectable adenylate cyclase activity in B. pertussis intact cells. Hewlett \& Wolff (1976) also reported that purified adenylate cyclase from $B$. pertussis lost $90^{\circ}$ of its activity after 20 min at $56^{\circ} \mathrm{C}$. Clearly, further investigation of the effects of $B$. pertussis adenylate cyclase on neutrophil function is needed. 
We thank Professor A. C. Wardlaw for his interest and suggestions during this work. Thanks also go to Professor G. T. Stewart, Dr J. Dolby, Dr F. Sheffield and Dr C. R. Harwood for strains of bacteria; Dr J. P. Durham for cAMP binding protein and Dr I. Pastan for anti-E. coli-CRP serum. R. M. B. was the recipient of a Science and Engineering Research Council studentship.

\section{REFERENCES}

Anderson, W. B. \& Pastan, I. (1973). The cyclic AMP receptor protein of Escherichia coli: immunological studies in extracts of Escherichia coli and other organisms. Biochimica et biophysica acta 320, 577 587.

APRILE, M. A. (1972). A re-examination of phase IV Bordetella pertussis. Canadian Journal of Microbiology 18. 17931801.

BOTSFORD, J. L. (1981). Cyclic nucleotides in procaryotes Microhiological Reriens 45, 620-642.

Brownlie, R. M., Parton, R. \& Coote, J. G. (1984). The effect of growth conditions on adenylate cyclase activity and virulence-related properties of Bordethlla pertusisis. Journal of General Microbiolog! 131 , 1725

Confer. D. L. \& Eaton, J. W. (1982). Phagocyte impotence caused by an invasive bacterial adenylate cyclase. Science 217, 948-950.

Cllliford. B. G. (1964). Precipitin reactions in forensic problems. Nature, London 201, 1092 1094

Dobrogosz, W. J., Ezzell, J. W., Kloos, W. E. \& Manclark. C. R. (1979). Physiology of Bordetella pertussis. In International Symposium on Pertussis, pp. 86-93. Edited by C. R. Manclark \& J. C. Hill. Washington, DC: US DHEW Publication no. (NIH) 79-1830.

Eisenstein, B. I., Beachey, E. H. \& Solomon, S. S. (1981). Divergent effect of cyclic adenosine 3',5'monophosphate on formation of type 1 fimbriae in different K-12 strains of Escherichia coli. Journal of Bacteriolog! 145, 620-623.

Eldering, G., Eveland, W. C. \& Kendrick, P. L. (1962). Fluorescent antibody staining and agglutination reactions in Bordetella pertussis cultures. Journal of Bacteriology 83, 745-749.

Ezzell, J. W., Dobrogosz, W. J., Kloos, W. E. \& Manclark, C. R. (1981). Phase-shift markers in the genus Bordetella: loss of cytochrome $\mathrm{d}_{629}$ in phase IV variants. Microbios 31, 171-182.

Goldhammer, R., WOlFF, J., COOK, G. H., Berkowitz. S. A., Klee, C. B., Manclark, C. R. \& HeWlett, E. L. (1981). Spurious protein activators of Bordetella perlussis adenylate cyclase. European Journal of Biochemistry 115, 605-609.

Hall, G. W., Dobrogosz, W. J., Ezzell, J. W., KloOs, W. E. \& Manclark, C. R. (1982). Repression of adenylate cyclase in the genus Bordetella. Microbios 33, 45-52.

Herbert, D., Phipps, P. J. \& Strange, R. E. (1969). Chemical analysis of microbial cells. Methods in Microbiology 5B, 209.334.

Hewlett, E. \& WolfF, J. (1976). Soluble adenylate cyclase from the culture medium of Bordetella pertussis: purification and characterization. Journal of Bacteriology 127, 890-898.

Hewlett, E. L., Urban, M. A., Manclark, C. R. \& WOLFF, J. (1976). Extracytoplasmic adenylate cyclase of Bordetella pertussis. Proceedings of the National Academy of Sciences of the United States of America 70, 2149-2152.

Hewlett, E. L.. Wolff, J. \& Manclark, C. R. (1978). Regulation of Bordetella pertussis extracytoplasmic adenylate cyclase. Advances in Cyclic Nucleotide Research 9, 621-628.

Hewlett, E. L., Underhill, L. H., Vargo, S. A., WolfF, J. \& MANClark, C. R. (1979a). Bordetella pertussis adenylate cyclase : regulation of activity and its loss in degraded strains. In International Symposium on Pertussis, pp. 81-85. Edited by C. R. Manclark \& J. C. Hill. Washington, DC: US DHEW Publication no. (NIH) 79-1830.

Hewlett, E. L., Underhill, L. H., Cook, G. H.. Manclark, C. R. \& WolfF, J. (1979 b). A protein activator for the adenylate cyclase of Bordetella pertussis. Journal of Biological Chemistry 254, 5602 5605.

Holt, L. B. \& Spasojevic, V. (1968). The role of surface antigens in the protective potency of Bordetella pertussis suspensions as measured by the intracerebral challenge technique in mice. Journal of Medical Microbiology 1, 119-126.

Idigbe, E. O., Parton, R. \& Wardlaw, A. C. (1981). Rapidity of antigenic modulation of Bordetella periussis in modified Hornibrook medium. Journal of Medical Microbiolog. 14, 409-418.

JebB, W. H. H. \& Tomlinson, A. H. (1951). The catabolic activity of washed suspensions of Haemophilus pertussis. Journal of General Microbiology 5 , 951-965.

KeOGh, E. V. \& North, E. A. (1948). The haemagglutinin of Haemophilus pertussis I. Haemagglutinin as a protective antigen in experimental murine pertussis. Australian Journal of Experimental Biology and Medical Science 26, 315-322.

LACEY, B. W. (1960). Antigenic modulation of Bordetella pertussis. Journal of Hygiene 58, 57-93.

LESLIE, P. H. \& GARDNER, A. D. (1931). The phases of Haemophilus pertussis. Journal of Hygiene 31, 423434.

Livey, I., Parton, R. \& Wardlaw, A. C. (1978). Loss of heat-labile toxin from Bordetella pertussis grown in Hornibrook medium. FEMS Microbiology Letters 3 , 203-205.

Martinez-Cadena, M. G., Guzman-Verduzco, L. M.. Stieglitz, H. \& Kupersztoch-Portnoy, Y. M. (1981). Catabolite repression of Escherichia coli heatstable enterotoxin activity. Journal of Bacteriology 145, 722-728.

Nealson. K. H. \& Hastings, J. W. (1979). Bacterial bioluminescence: its control and ecological significance. Microbiological Retiews 43, 496-518.

OrlowsKI, M. (1980). Cyclic 3',5'-monophosphate binding protein in developing myxospores of $M_{1}: x_{0}-$ coccus xanthus. Canadian Journal of Microbiology 26, 905-911. 
Parton, R. \& Durham, J. P. (1978). Loss of adenylate cyclase in variants of Bordetella pertussis. FEMS Microbiology Letters 4, 287-289.

Parton, R. \& Wardlaw, A. C. (1975). Cell-envelope proteins of Bordetella pertussis. Journal of Medical Microbiology 8, 47-57.

PASTAN, I. \& Adhya, S. (1976). Cyclic adenosine 3',5'monophosphate in Escherichia coli. Bacteriological Reviews 40, 527-551.

Pastan, I., Gallo, M. \& Anderson, W. B. (1974). The purification and analysis of mechanism of action of a cyclic AMP-receptor protein from Escherichia coli. Methods in Enzymology 38C, 367-376.

PuszTai, Z.\& Joó, I. (1967). Influence of nicotinic acid on the antigenic structure of Bordetella pertussis. Annales immunologicae hungaricae 10, 63-67.

Roberts, M. E. \& Ospeck, A. G. (1942). Pertussis toxin. Journal of Infectious Diseases 71, 264-269.

Robinson, A., Gorringe, A. R., Irons, L. I. \& KeEvil, C. W. (1983). Antigenic modulation of Bordetella pertussis in continuous culture. FEMS Microbiology Letters 19, 105-109.

ShapIRO, L. (1976). Differentiation in the Caulobacter cell cycle. Annual Review of Microbiology 30, 377407.
Stainer, D. W. \& Scholte, M. J. (1971). A simple chemically defined medium for the production of Phase I Bordetella pertussis. Journal of General Microbiology 63, 211-220,

Tait, R. C., Anderson, K., Cangelosi, G. \& ShanmugaM, K. T. (1981). Hydrogenase genes. In Trends in the Biology of Fermentation for Fuels and Chemicals, pp. 279-304. Edited by A. Hollaender. New York: Plenum Publishing Corp.

Wardlaw, A. C. \& Parton, R. (1979). Changes in envelope proteins and correlation with biological activities in B. pertussis. In International Symposium on Pertussis, pp. 94-98. Edited by C. R. Manclark \& J. C. Hill. Washington, DC: DHEW Publication no. (NIH) 79-1830.

Wardlaw, A. C., Parton, R. \& Hooker, M. J. (1976). Loss of protective antigen, histamine-sensitizing factor and envelope polypeptides in cultural variants of Bordetella pertussis. Journal of Medical Microbiology 9, 89-100.

Weiss, A. A. \& Falkow, S. (1984). Genetic analysis of phase change in Bordetella pertussis. Infection and Immunity 43, 263-269. 